\section{PSYCHOSTATS 2.1: A statistics package in OS-65U BASIC}

\author{
LIONEL STANDING \\ Bishop's University, Lennoxville, Quebec, Canada \\ and \\ LESTER GILBERT \\ Synertek, Ltd., Sheffield, England
}

PSYCHOSTATS, the set of statistics programs produced by Gilbert (1979) for the Hewlett-Packard 2114B, has been translated into Ohio Scientific 65U BASIC. Some small errors have been corrected, and many new programs have been added. The resultant package, termed PSYCHOSTATS 2.1, has been tested by approximately three years of use in a computing center. The package is menu driven and now includes programs for the management and use of data files. A 260-page user manual provides descriptive material, limiting conditions and sample output for each program.

The package now comprises 64 programs, grouped in the following categories (the number of programs in each group is given in parentheses):

The authors' mailing addresses are: Department of Psychology, Bishop's University, Lennoxville, Quebec, Canada J1M 1Z7; and 6 New Houses, Green Moor, Wortley, Sheffield S30 7DQ, England.
Menu

Student's $t$ test-(4)

ANOVA for independent groups-(3) 1 to 3 way. ANOVA with repeated measures-(5) 1 to 3 way.

Correlation and regression-(13) Simple and multiple.

Analysis of covariance-(3) 1 and 2 way.

Chi-square and cross tabulation-(3) 1 and 2 way.

Latin square-(2)

Post-ANOVA comparison-(5) Main effects and multiple comparisons.

Nonparametric tests-(5)

Data file management-(9)

Descriptive statistics and data transformations-(8)

User assistance-(3)

Language and Computer. The package is written in OS-65U BASIC for any Ohio Scientific computer with at least $24 \mathrm{~K}$ of workspace. A printer and hard disc are required.

Availability. The complete package, with user manual, is available on tape without charge. Please send a blank 9-track half-inch magnetic tape $(600 \mathrm{ft}$ minimum) to the first author.

\section{REFERENCE}

GILBERT, L. H. (1979). PSYCHOSTATS: BASIC programs for data analysis in psychology. Behavior Research Methods \& Instrumentation, 11, 464. 